\title{
Smallholders perception on the roles of extension agent - coconut industry sustainability in Tanjong Karang, Selangor, Malaysia
}

\author{
Rusli, A.L. and *Isa, N. \\ Faculty of Plantation and Agrotechnology, Universiti Teknologi MARA Melaka Branch, Jasin Campus, \\ 77300 Merlimau, Melaka
}

\section{Article history:}

Received: 23 April 2021

Received in revised form: 13 July 2021

Accepted: 27 November 2021

Available Online: 30

November 2021

\section{Keywords:}

Smallholder,

Perception,

Roles,

Extension Agent,

Coconut Industry,

Sustainability

DOI:

https://doi.org/10.26656/fr.2017.5(S4).013

\begin{abstract}
This study was conducted to analyse the smallholder's perception of the roles of extension agents - coconut industry sustainability. To ensure the extension agent program is successful, the agent should recognize their roles as the change agent in the coconut industry which is, they act as a catalyst, process helpers, resource linkers, and solution giver. This study was conducted in sub-districts of Kuala Selangor at Tanjong Karang. The sample of fifty-six respondents was selected from the 65 population through the random sampling method. By using a survey method, the questionnaires were distributed to measure the roles of the extension agent as a change agent based on the smallholder's perception. Based on correlation coefficient analysis, it was shown that all data was significant between catalyst, process helper, resource linker, and solution giver by using 0.10 (p-value). The highest correlation coefficient in this analysis is solution giver that shows the correlation value 0.660 and can best be described as a positive strong relationship. The result for multiple linear regression showed that process helper was the dominant factor for this study which showed the beta, $p$-value is 0.264 by using 0.10 (pvalue). Hence, it can be analysed that the level of the extension agent roles in the coconut industry is at a medium level because they are not fully utilizing their roles as a change agent. As for the recommendation, extension agents in the coconut industry should be more aggressive by looking at the various aspects such as communication, decision making, knowledge, skills, and others to make the coconut industry sustainable for the future.
\end{abstract}

\section{Introduction}

In Malaysia, most agricultural industries have an extension agent in order to give them guidelines and monitor the productivity of the farm or plantation area, so do coconut industries. Extension agents in the coconut industry must approach the new strategies that rely on the current development of the technology with topdown development without having a framework for feedback from the farmers in the way to make the coconut industry sustainable. In more recent years, when the extension agent started to shift towards greater farmer participation it was difficult especially regarding the new technology and the extension agent needed the patience to elicit smallholder's response. Commonly, extension agents know their roles, but mostly they are using other people to handle and manage the issues that are related to the coconut industry in Malaysia. In terms of the extension agent specialist, they must have an expanded specialized competency in more than one program to face the smallholders from the coconut industry background (Shah et al., 2013). So, here the extension agent needs to make perfect potential that is needed by the global interest which can grow socially and environmentally that responsible way known as the sustainable coconuts has grown (USAID, 2019). As we know, they have some issues that make the coconut crops become prior is this study when the coconut production area decreased that lead to the several problems such as firstly, is lack of proper management practices in every state especially in this research area. Based on the observation by Saha and Che Mat (2018) coconut is mostly grown in the uncared area without proper irrigation and fertilizer application because mostly the smallholders will be preferred using the traditional cultivation and this will cause major issues that can decline the coconut productivity. Secondly, the sustainability of the farming method, based on the past research they have noticed the traditional method is 
lacking in the procedure for selecting old coconut palm and unproductive areas. Similarly, it is critical to identify weeds and pests early in the growing season in order to ensure normal growth and the selection of high-quality seedlings for a higher yield of long-term productivity increase. Thirdly, smallholders lack awareness regarding the information about coconuts such as soil type, soil $\mathrm{pH}$, organic material at the area of the field and many more. In this scenario, little is known about the underlying process that allows smallholders to view plant data. Despite this, few types of research look into the impact of seasonal climatic conditions on coconut output, as well as the relative effects of solar radiation and air pressure on yield (Saha and Che Mat, 2018).

On a surprising note, the other problems are when smallholders blame the extension agent due to the decline of the production for the coconut industry at the certain area in Malaysia which lead to the selfdependency of the smallholder by using the traditional method rather than using the new technologies (Alukha and Regmi, 2013). According to the Saidia et al. (2010) smallholders do not get any benefit from the government initiatives of the crop grown and, they have failed to get benefits from the extension agents. So, here we can see that the roles of the extension agent are not performed well, and these issues need more research to give them a better input on how to be an effective agent under the government agencies for the coconut industry. The purpose for choosing this crop rather than other crops is crop because coconut is one of the crops that will be major crops for Malaysia in the future. Thus, Malaysia is one of the coconut producers at $12^{\text {th }}$ ranking number among top 20 countries but the area of planting coconut in Malaysia from 2016 - 2018 was reduced from 84,609 ha to 81,585 ha hence, the production of the coconut was increasing only up to 21,096 metric tons differ with the other plantation industry in Malaysia like oil palm, rubber, paddy, and others (Department of Agriculture Malaysia, 2018). So, all extension agents in the coconut industry must approach the new strategies that rely on the current development of the technology with topdown development without having a framework for feedback from the farmers. In more recent years, when the extension agent started to shift towards greater farmer participation it was difficult especially regarding the new technology and the extension agent needed patience to elicit farmer response (Shah et al., 2013).

Other than that, to quicken the development of the coconut industry and become more sustainable, the extension agent that has been given a task by the government must have to play an enormous part in guaranteeing that buyers get a reliable and reasonable supply of coconuts while progressing the vocation of ranchers. Malaysia urgently needs to revive this future market of the coconut industry even though this crop may not be the number one crop in Malaysia. At this point, Malaysia must make a few efforts to move forward and donate modern breath to the coconut industry. Besides that, to ensure the effectiveness and efficiency of the program implementation regarding the coconut industry, the government in the Asian countries should strengthen the National Coconut Extension Agent Service (NCEAS) so that they can make delivery services to coconut smallholders around Malaysia (Department of Agriculture, Forestry, and Fisheries, Republic of South Africa, 2012). We know that the extension agent is the most important for any single crop in the world because they will give a lot of ideas through the improvement of coconut sustainability such as for the planting techniques, marketing, harvesting, and others. Based on this study, it was given a lot of benefits and more contribution to the various sectors such as to the smallholders themselves. Smallholder is a group of people that manage their plantation area with the benefits of crop production. If the roles of extension agents are being fully utilized, it can give high value to the coconut industry smallholders because from the extension services smallholders know the roles of the extension agent and will help to strengthen the human capital for the smallholders' area and to the coconut sustainability as well.

Other than that, this study also gives a benefit to the government because the extension agent commonly will approach by delivering the national government strategy and method to the coconut industry smallholders or rural areas. They also can be utilized both in political control and to beat the proficient officers in the government sector by helping through the implementation of the national agricultural development program. Besides that, other researchers also will get the benefits from this study because the extension agents can offer the assistance specialist to the researcher to understand more about the issues and the limitations that have been faced by the smallholders and much better if the researcher is bringing directly close to the smallholders, where it can ensure that the researcher suggestions are reliable to the smallholders' needs. Sometimes, smallholders discover all the problems with their recommendations because the researcher failed to note the issues and problems. This research also can be used as a reference to the other researcher that studies the extension agent on the coconut industry because with the response of all the recommendations it can be arranged according to the timeline from the government. Hence, this research is aimed to study the smallholder's perception of the roles of extension agents and to determine the dominant smallholder perception of the roles of extension agents in 
coconut industries.

\section{Materials and methods}

\subsection{Sample size}

The study was carried out in Tanjong Karang, Kuala Selangor, Selangor. About $70 \%$ of the people in Tanjong Karang, Kuala Selangor, Selangor are engaged in planting the coconut crop. The study area was selected purposely for the reason to know the smallholder's perception on the roles of extension agents because this area is the top three coconut production in the Selangor state that has been reported by the Department of Agriculture (DOA), Selangor. This location has an area of 2,997.74 hectares under Kuala Selangor district only. All the coconut smallholders in this area are actively planting the coconut industry, which is being registered under the DOA. So, this study also showed that extension agents were the resource person that helped them to be more active in producing the high production of the coconut (Jabatan Pertanian Negeri Selangor, 2020). The major criteria for selecting this population because this area kept improving the production of the coconut which led to the increasing number of coconut production in Malaysia and the world. This was the focus area where the smallholder's perception was tested regarding whether the extension agent services are rendered to them or not. Based on the study, sample design is a very important aspect of making a survey because it can be a road map or framework which serves as the basis for selecting any of the survey samples. Survey researchers are interested in collecting a kind of knowledge in a specific sense through a survey of interest for some society, or universe.

Based on Kabir (2006) there are several types of sampling which are random sampling, stratified sampling, cluster sampling, and systematic sampling. Random sampling was chosen by the researcher in this study in which the population is numbered in each of the members or selected randomly based on race, age, gender, and culture. This method is widely used in all studies because it can avoid the biased result of the study and can obtain a good result. Hence, in this study, the purpose of using the random sampling method is because each sample has an equal probability of being chosen. A randomly chosen sample is meant to reflect the objective coverage of the total population.

Based on the Krysik and Finn (2007) described the general sampling as the element that was selected until the observation or no new insight is revealed. For this sample size, which the study that was carried on, the sample size was determined by the look of the production of the crop in that state and the roles of the extension agent toward the smallholder perception. So, the sample size of the study is analyzed by using Krejcie and Morgan tables to have an accurate sample size according to the population size. Thus, the overall sample size that is needed in this study is 56 smallholders out of 65 total population in the coconut industry at Tanjong Karang, Selangor. Based on this research, when the researcher distributes the questionnaires to the smallholders, all of them was given good feedbacks and were full of commitment in the way to improve the function of the extension agent in the coconut industry and from the survey, it was shown the positive scale because they noticed that the extension agent are fully utilized to them in the coconut industry.

\subsection{Questionnaire}

The data that is used in this study is using quantitative data, where it uses the statistical analysis method to test the relationship between the variables. Data for this study was collected through the distribution of the questionnaires to the respondent during the physical general meeting of the smallholders with the Department of Agriculture, Kuala Selangor. The questionnaires were explained to the smallholders in question using English and Bahasa or known as dual language. Thus, based on the survey instrument results, it was suitable for the actual study. These questionnaires were distributed after the reliability test was done. The reliability test was done to check the reliability of the questionnaires for the smallholders to answer. The reliability of the question is considered as a reliable question to use when Cronbach's Alpha is $\geq 0.70$ and this test only uses $10 \%$ of the respondent from the population of the study (Goforth, 2015). The use of the Cronbach's Alpha is to ensure the internal consistency or a composite score, reliability has been assessed to the set of scales whereas if the questionnaires are reliable to be as a question the scaling must be more than 0.70 but if the scales below than 0.5 when it is testing using the Cronbach's Alpha the questionnaires was unacceptable to be distributed to the respondent (Goforth, 2015).

In other words, to ensure consistency during applying the data, the reliability of any measurement is referring to the extent, hence Cronbach's Alpha is one of the best methods that can give the strength of the data consistency. The correlation was computed by Cronbach's Alpha for each of the items with the total score during observation. The alpha coefficient of the reliability changes was around 0 to 1 during providing the overall study. If the alpha is equal to 0 the scale items were entirely independent of one another. For example, the study is not correlated and has no covariance. But if the alpha is equal to one the infinity number will appear in the scale approaches (Goforth, 2015). Hence, the data 
collected was analysed by using the Statistical Package for Social Science (SPSS) software. Since the data are collected and evaluated in a statistically accurate manner, the results of the quantitative analysis can be easily summarized and used to systematically describe the large collection of the things in the survey study that can generate reproducible knowledge.

Based on the Figure 1, it was shown the relationship between the independent variable such as catalyst, process helper, resource linker, and solution giver with the dependent variable smallholders perception on the extension agent roles. Catalyst is a change agent that acts as a person who has responsibilities and assumes responsibility for overseeing the alter program or activity within the organization. In the extension aspect, the initiator of changed conduct is known as an alter specialist. The change agents can be directors or nonmanager, workers of the organization that give the consultancy to the people through the correct services and information (Pathak, 2010). Extension agents also must interact with the people or clients in formal or informal ways. Thus, they must have a good attitude to their works which can give a positive perception to the people (Shah et al., 2013). Process helper is the most comprehensive in the change agent. The person who is in the process helper will lead to giving the fullest assistance to the client at every single stage to solve the problem which works toward the internal capacity for problem-solving. Process helper is the major change for all the change agents because it must have a concentrated effort to ensure that the changes from one stage to another level is perfect (Ronald Havelock et al., 2020). A resource linker is the largest part of the successful exchange. Based on the study, each of the people has their problem and commonly extension agents have a good knowledge that has been useful to manage the problem. Extension agents are also known as resource linkers because they will help other people especially the farmers or smallholders regarding the quality of the production (Havelock and Zlotolow, 2021). Based on the study, the solution giver is the most common role for extension agents to guide people because the solution giver is always giving the perfect solution to solve the issue or problem. As the solution giver, they always try and adapt to a specific change or innovation before sharing the knowledge and idea with the client. Some of the solution givers are seeking knowledge from the experts to ensure the information channel that they created will help and guide the client in an efficient method. They also make a high effort to help the client make a decision and analyse the fact before the client receives the information. The solution giver also usually has a diverse and flexible solution that might be helpful as a resource for the client (Havelock and Zlotolow,
2021).

Hence, based on all the independent variables it totally will give the perception to the smallholders in the way to know better about the roles of extension agents in the coconut industry because the roles of extension agents are the one model that can be appropriate to all the circumstances. As a specialist, they must consider each of the circumstances independently and receive a position by using a piece of reasonable information regarding the situation. This shows that the roles of the extension agent can bring changes to agriculture especially among the smallholders or farmers. As extension agents, they also play a role to recognize the issues and to overcome the issues that have been faced by the farmers and accomplish the sense of fulfilment to achieve targets based on the suitable guideline. Then, as an agent in the professional sector, they also must be able to influence the innovation and decision-making process which can be transferred to other people (FAOSTAT, 2020).

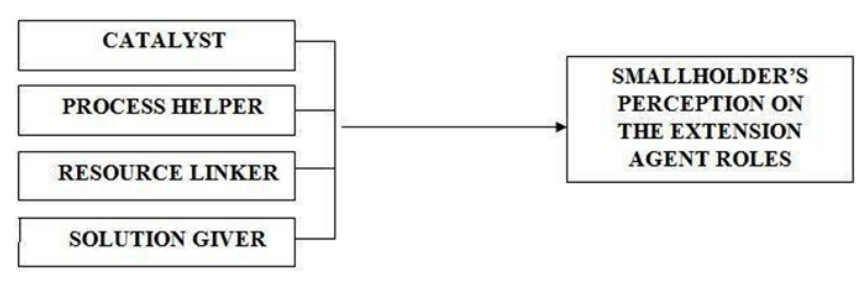

Figure 1. Theoretical framework

Source: Roles of Extension Agents Towards Agricultural Practice in Malaysia (Shah et al., 2013).

\subsection{Reliability analysis}

The reliability test was done to check the reliability of the questionnaires for the smallholders to answer. The pilot test was using $10 \%$ or 7 of the respondents from the total population in this study. The reliability of the question is considered as a reliable question to use when Cronbach's Alpha is $\geq 0.70$. The use of the Cronbach's Alpha is to ensure consistency during applying the data, the reliability of any measurement is referring to the extent, hence Cronbach's Alpha is one of the best methods that can give the strength of the data consistency (Goforth, 2015).

\subsection{Descriptive analysis}

Descriptive analysis is used to define the basic characteristics of the study data into a simple form. The descriptive analysis was a simple action of the research study and provides valuable information about the individual and the group of the study.

\subsection{Pearson's correlation coefficient analysis}

Correlation is another way to evaluate the 
relationship among variables. More specifically, it tests the degree of interaction between the two variables by random. There is a great deal of similarity between regression and correlation but for their methods of relationship interpretation.

\subsection{Multiple linear regression analysis}

Multiple linear regressions are the technique that is used statistically for estimating among variables of the relationship which has a result relation and reason. The multiple linear regression analysis assumptions such as linearity, normality, no extreme value, and missing value analysis were examined. The method of multiple linear regression helps to establish a correlation between the independent and dependent variables (Gulden Kaya Uyanik, 2013).

\section{Results and discussion}

Data analysis is the process of evaluating and transforming the data to get useful information for the study research. The basic tools used are Statistical Packages for Social Science (SPSS). There are several types of data analysis involved in this study which are descriptive analysis, correlation analysis and multiple linear regression. For the correlation analysis and multiple linear regression analysis, it will use the 0.10 (p -value) as the indicator for the significance level in this study. Based on the observation from a study by Figueiredo Filho et al. (2013) most statistical research study the rules of thumb of $0.1,0.05,0.01$ is the level for the significance level. So, in this study, the researcher chose to use the 0.10 (p-value) after careful consideration of the several key factors in this study such as the sample size, the power of the test in this study, and the expected losses from the type I and II errors. However, the conventional level 0.05 significance level still will be as the practical benchmarks and should not have been adopted mechanically and mindlessly in every application of the research study (Kim, 2015). Hence, the significance level must indicate the amount required in the study because the p-value will be as a strength of the evidence which exists in this research study, so when the $\mathrm{p}$-value is less or equal to the significance level it has high evidence that meets the evidentiary standard for rejecting the null hypothesis, Ho (Frost, 2020).

\subsection{Reliability analysis}

Table 1 shows the value of the Cronbach's Alpha for the questionnaires is 0.894 by using 7 respondents from smallholders, $10 \%$ of the total population. The reliability result for all components in the pilot study shows a value greater than 0.70 . Based on the research, if the reliability test is $\geq 0.70$ or higher is considered acceptable in most social science research.

Table 1 . Reliability test.

\begin{tabular}{ccc}
\hline \multicolumn{3}{c}{ Reliability Statistics } \\
\hline $\begin{array}{c}\text { Cronbach's } \\
\text { Alpha }\end{array}$ & $\begin{array}{c}\text { Cronbach's Alpha Based on } \\
\text { Standardized Items }\end{array}$ & N of Items \\
\hline 0.894 & 0.901 & 25 \\
\hline Source: Statistical Package for Social Science (SPSS), 2020
\end{tabular}

\subsection{Demographic analysis}

Respondents of this study mostly come from the male's smallholders $(73.21 \%)$ that manage coconut crops and the average year of the respondents are above 60 years old $(51.79 \%)$. Other than that, most of the smallholders are having a secondary school level (66.07\%) but for the other smallholders, they have completed their primary school, diploma, and bachelor's degree program. They are also already married with $60.71 \%$ having a monthly income level around RM 1000 - RM 2800. Based on the data collected it was clearly stated that employment status for 56 respondents by demonstrating the highest one is $85.71 \%$, which is a fulltime coconut smallholder and the other respondents make a coconut industry as a part-timer and will be fulltime when they retire later. Besides that, it also shows the involvement of the smallholder in the coconut industry, which at the highest level is $42.86 \%$ consistent with more than 10 years of participation in the coconut industry. Lastly, most $96.4 \%$ of smallholders are satisfied with their work nowadays while the others are not satisfied with their job because of the issues and problems faced by them during working time.

\subsection{Pearson's correlation coefficient analysis}

Based on the Table 2, it was showing the data that are used to interpret the relationship between the independent variable and the dependent variable for this research study, which is when the r-value range 1.0 was considered as a positive relationship and for the $r$-value is -0.10 , it was considered as a negative relationship of

Table 2. Pearson correlation coefficient analysis result.

\begin{tabular}{llc}
\hline $\begin{array}{c}\text { Independent } \\
\text { variable }\end{array}$ & $\begin{array}{c}\text { Smallholder's Perception of } \\
\text { the extension agents' roles }\end{array}$ \\
\hline \multirow{3}{*}{ Catalyst } & Pearson Correlation & $0.594^{*}$ \\
& Sig. (2-tailed) & 0 \\
& $\mathrm{~N}$ & 56 \\
\hline \multirow{2}{*}{ Process } & Pearson Correlation & $0.640^{*}$ \\
helper & Sig. (2-tailed) & 0 \\
& $\mathrm{~N}$ & 56 \\
\hline \multirow{2}{*}{ Resource } & Pearson Correlation & $0.588^{*}$ \\
linker & Sig. (2-tailed) & 0 \\
& $\mathrm{~N}$ & 56 \\
\hline \multirow{3}{*}{ Solution giver Sig. (2-tailed) } & Pearson Correlation & $0.660^{*}$ \\
& $\mathrm{~N}$ & 0 \\
\hline
\end{tabular}

*Significant at $10 \%$ level 
correlation that should be as follows.

The first independent variable for this study is a catalyst that shows a correlation value as much as 0.594 , and the significant value is 0.00 , which means there is a significant correlation between the relationships of this study. Hence, the hypothesis alternative or $\mathrm{H}_{1}$ is accepted and can be concluded that there is a significant relationship between a catalyst and the smallholder's perception of the extension roles because based on the observation, a catalyst will act as the way that is needed to overcome the problem that has been faced by the coconut smallholders (Makapela, 2015). As studied by other researchers, the catalyst can also be considered the change agent that always actively supports the smallholders for developing the new initiative by tackling their problems with the help of the extension agent as guidance (Rohrich and Sullivan, 2012).

Other than that, the second independent variable for this study is the process helper, which shows the correlation value is 0.640 and the significant value is 0.00 , which means there is a significant relationship between this study. Hence, the hypothesis alternative or $\mathrm{H}_{1}$ is accepted and can be concluded that there is a significant relationship between process helper and the smallholder's perception on the extension agent roles because based on the previous study, process helper will play their vital role by showing the people how to set the flow, to identify smallholders needs and diagnose the problems. Other than that, the process helper will also help the smallholders, acquire the relevant resources, and give the adaptation and installation of the solution for producing the proper management for coconut crop (Havelock, 1973).

Furthermore, the third independent variable for this study is the resource linker, which shows the correlation value is 0.588 and the significant value is 0.00 , which means there is a significant correlation between the relationships of this study. It is not more than 0.10 (pvalue). So, the hypothesis alternative or $\mathrm{H} 1$ is accepted and can be concluded that there is a significant relationship between the resource linker and the smallholder's perception on the extension agent roles because based on the prior study by the expert researcher, resource linker can be interpreted as a change agent that brings the resources to the smallholders together in the way to aid in the solution of issues (Deszca et al., 2019). Then, resource linkers can also be useful to the smallholders by developing a wide range of networks to the other agricultural agencies to understand the smallholder's needs through better communication (Rohrich and Sullivan, 2012).

The last independent variable for this study is the solution giver, which shows the correlation value is 0.660 . The significant value is 0.00 , which means there is a significant relationship between this study. It is not more than 0.10 (p-value). So, the hypothesis alternative or $\mathrm{H} 1$ is accepted and can be concluded that there is a significant relationship between the solution giver and the smallholder's perception of the extension agent roles because solution giver is the agents that provide definite ideas and have a lot of solution to adopt the problems as well as convince others to pursue the solutions because these change agents will give a lot of commitment to managing the particular issues with the proper solutions in the way of understanding to the resistance solutions or real problem that they are advocating. Hence, an effective solution giver also requires more than input in having a solution and teaches others how it relates to the smallholder's concerns and needs (Deszca et al., 2019) (Havelock, 2020).

\subsection{Multiple linear regression analysis}

Table 3 shows the model summary for the multiple linear regression analysis. Based on Table 3 above, the first showing is the statistic of R-value is the multiple linear correlation coefficient between all the predictor variables of this study and the smallholder's perception on the extension agent roles. In this model, the R-value is 0.746 , indicating the strong and high deal of the variance shared by the independent variables. Thus, the value of $\mathrm{R}$ - squared, $\mathrm{R}^{2}$ is 0.556 , which shows $55.6 \%$ of the variation in the dependent variable, which is the smallholder's perception on the extension agent roles is explained by all the independent variables which are the catalyst, process helper, resource linker, and solution giver in the regression model but the other factor explains the balance $44.4 \%$. From the value of the $\mathrm{R}-$ squared, it can best be determined as the value 0.556 is the moderate multiple linear regression, which is it can be a good model for a particular study due to the several factors such as the data outcomes from the respondent, human behaviours, and others factor that can be considered as an unpredictable (Francis, 2020).

Table 3. Model Summary

\begin{tabular}{ccccc}
\hline \multicolumn{5}{c}{ Model Summary } \\
\hline Model & \multirow{2}{*}{$\mathrm{R}$} & $\begin{array}{c}\mathrm{R}- \\
\text { Squared }\end{array}$ & $\begin{array}{c}\text { Adjusted R } \\
- \text { Squared }\end{array}$ & $\begin{array}{c}\text { Std. Error of the } \\
\text { Estimate }\end{array}$ \\
\hline 1 & $0.746^{\mathrm{a}}$ & 0.556 & 0.552 & 0.36927 \\
\hline
\end{tabular}

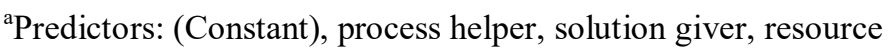
linker, catalyst

This means every increasing unit of the change agents, which are process helper 0.264 , solution giver 0.257 , resource linker 0.172 , and catalyst 0.145 , are able to enhance the smallholder's perception on the extension agent roles. So, the most dominant factor, which is process helper based on the higher beta, $\beta$ where it was a 
greater influence on the smallholder's perception on the extension agent roles.

Based on Table 4 in this study, the dependent variable is the smallholder's perception of the extension agent roles. In contrast, the independent factor is the catalyst, process helper, resource linker, and solution giver. Hence, the result showed two independent variables that are process helper and solution giver were significant with the smallholder's perception of the extension agent roles but the other two independent variables which are the catalyst, and resource linker were not significant to the dependent variable. Thus, based on the data above, this study shows the dominant factor is the process helper with the beta, the $\beta$ value is 0.264 , and the highest factor among the others at the significance value is 0.054 (p-value), which is below than 0.10 level.

Other than that, based on Ali Hassan et al. (2008) and Radhakrishna et al. (1991) extension agent is the type of leadership that will bring the smallholders to give the increasing critical thinking element into the successful. Based on this study, the process helper is the dominant factor that gives high perceptions to the smallholders to ensure all the smallholders have a raised awareness regarding the involvement of the extension agent as the process helper. The key element that makes the process helper most dominant is whenever the extension agent acknowledged their skills and performance in the various expect such as coordinate capital, guiding the smallholders in the proper process to accomplish the goal because usually, they will be located at the rural community for giving the command of chains as a leader to smallholder to take a relevant and better action (Ali Hassan et al., 2008). The previous study by Kunwar (1989) has stated the extension agent is the person who regardless has the position and title in the way to perform the job performance to give the services to the smallholder such as process helper can be recognized as the person that always helps the smallholders to show on how to use all the needs, gain relevant resources which can give the high benefits to the smallholders.

Other than that, process helper becomes the dominant factor in this study because they play their essential roles act as an educator for selecting and creating the solution or suggest the new alternative courses of solution and action for consideration by Beal (1981) if the smallholders faced a problem regarding on the coconut industry such as technologies usage, planting method, the usage of fertilizer, and others because basically, the extension agent will translate all the intent into the real action for widely uses in order to prevent the discontinues of the application and at the same time it can make the stabilization adoption of the implementation (Kunwar, 1989). Hence, the support system in the future by improving the socialization and make emotional aspects is the important way to increase the perception of the extension agent as the change agent due to the environment that globally has grown rapidly. All the roles of change agents need to be more interrelated between each other and complex in any programming that can be the main approaches in the development of the coconut industry. Thus, the extension agent also needs to be more effective at a different mindset by Ismail (2012) in order to make a difference. All of the changes can be proved with the proper understanding of the roles of extension agents in the coconut industry by the top management (Shah et al., 2013).

Hence, based on this study they have some limitations during taking the survey, especially that the researcher needs some time to reach the smallholders in the coconut industry because most of them are coming from the eldest person and the time taken to understand the question was a bit long. As we know, this study also lacked previous studies in the research area and will give the effect also to the sample size that was used. The main

Table 4. Multiple linear regression analysis.

\begin{tabular}{lccccc}
\hline \multirow{2}{*}{ Model } & \multicolumn{2}{c}{ Unstandardized Coefficients } & Standardized Coefficients & \multirow{2}{*}{$t$} & \multirow{2}{*}{ Significance } \\
\cline { 2 - 4 } & Beta, $\beta$ & Std. Error & Beta, $\beta$ & & \\
\hline (Constant) & 0.916 & 0.455 & & & \\
Catalyst & 0.145 & 0.143 & 0.142 & 1.104 & 0.049 \\
Process Helper & 0.264 & 0.134 & 0.280 & 1.970 & 0.315 \\
Resource Linker & 0.172 & 0.126 & 0.188 & 1.363 & 0.179 \\
Solution Giver & 0.257 & 0.136 & 0.276 & 1.895 & $0.064^{*}$ \\
\hline
\end{tabular}

*Significant at $10 \%$ level.

The estimated regression equation for the model was formulated as follow:

$\mathrm{Y}=\alpha+\beta \mathrm{X}$

$\mathrm{Y}=0.916+0.264 \mathrm{X}_{1}+0.257 \mathrm{X}_{2}+0.172 \mathrm{X}_{3}+0.145 \mathrm{X}_{4}$

Where, $\mathrm{Y}=$ Smallholder's perception on the extension agent roles, $\alpha=$ Constant, $\mathrm{X}_{1}=$ Process helper,

$\mathrm{X}_{2}=$ Solution giver, $\mathrm{X}_{3}=$ Resource linker and $\mathrm{X}_{4}=$ Catalyst 
purpose of using the specific number of the sample size because this will be as the perfect data for this research area only and will make improvement with the sample size for the next research data and to ensure this study will be as the guideline to the other researcher to perform better when conducting the survey that related to the extension agent in the coconut industry. Lastly, the scope of discussion is the other limitation because the researcher does not have many years of experience in conducting the research as compared to the experienced researcher. But this will be improved as the way to make this study become better and as a source of references to others.

\section{Conclusion}

In conclusion, this study successfully identified the smallholder's perception of the roles of extension agents and determined the dominant smallholder perception of the roles of extension agents in coconut industries. It was shown that all the independent variables which are the catalyst, process helper, resource linker, and solution giver were significant to the smallholder's perception of the extension agent roles. In order to be a competent extension agent in the coconut industry, they should have several aspects such as technical skills, knowledge, and personal characteristics that can lead them to have outstanding performance as the extension agent. Then, it can be concluded that the process helper is the most dominant factor as the change agent in the coconut industry that always gives support to the coconut smallholder.

Understanding the extension agent roles could be through an introduction or strong planning for both extension agent and the coconut smallholders in order to transfer the current skills and technical problems regarding the new era of the agriculture sector by using the current information on the market development. Extension agents can help to increase productivity and improve the development of the coconut industry because this kind of crop will be a future major crop for Malaysia and other countries in the world. So, with the helplessness and guidance from the extension agent, it will give the high impact to sustain the good practice and guide smallholders to develop the quality of coconut crops.

\section{Conflict of interest}

The authors declare no conflict of interest.

\section{Acknowledgements}

I would like to express my deepest gratitude to my principal supervisor, Madam Nurulain Binti Isa for her constant guidance and support from the start of the project, analysing the data, and until the end of the research by giving me fullest attention and time to supervise me. My sincere thanks to the Department of Agriculture Kuala Selangor, that helped me to meet with the coconut smallholders and to my friends $\mathrm{Mr}$ Mohamad Aidil Mohd Fauzi and Mr Shahrul Hakem Mohamed Shahrom who assisted me during questionnaire distribution. My sincere thanks also go to Miss Nuraslisa Aiza Binti Mohd Hamiruz and Miss Zubaidah Binti Omar who guide me to analyse the data in this research project. Then, I would like to thank my beloved family that always supports me by providing all the facilities to finish this research study. Lastly, thank you to the Faculty of Plantation and Agrotechnology for giving me an opportunity to conduct this study by giving the fullest motivation and support.

\section{References}

Ali Hassan, O.K., Ismail, M., Suandi, T. and Silong, A.D. (2008). Commitment on Extension Workers' Performance. The Journal of International Social Research, 1(4), 368-389.

Beal, G.M. (1981). The change agent and change-agent roles. Extension Education and Rural Development. Vol. 2, p. 109 - 121. New York, USA: John Wiley and Sons.

Department of Agriculture Malaysia. (2018). Booklet Statistik Tanaman Sub-Sektor Tanaman Makanan 2018. In Jabatan Pertanian. Retrieved on August 16, 2020 from Website: http://www.doa.gov.my/index/ resources/aktiviti_sumber/sumber_awam/ maklumat_pertanian/perangkaan_tanaman/ booklet_statistik_tanaman_2018.pdf

Department of Agriculture, Forestry and Fisheries, Republic of South Africa. (2012). A framework for the development of smallholder farmers through cooperative development. Retrieved from website: https://www.nda.agric.za/doaDev/sideMenu/ cooperativeandenterprisedevelopment/docs/ FRAMEWORK-\%20OF\%20SMALL \% 20FARMERS\%20(2).pdf

Dezca, G., Ingols, C. and Cawsey, T.F. (Eds.) (2019). Becoming a Master Change Agent. In Organizational Change. $4^{\text {th }}$ ed. USA: SAGE Publishing, Inc.

FAOSTAT. (2020). 6. The extension agent. 1-8. Ch08. (2021). Retrieved July 4, 2020, from FAO Website: http://www.fao.org/3/t0060e/t0060e08.htm.

Figueiredo Filho, D.B., Paranhos, R., Rocha, E.C.D., Batista, M., Silva Jr., J.A.da, Santos, M.L.W.D. and Marino, J.G. (2013). When is statistical significance not significant? Brazilian Political Science Review, 7 (1), 31-55. https://doi.org/10.1590/s1981- 


\section{2}

Francis, A. (2020). Interpreting the correlation. Retrieved from Exam Prep Mths Apps website: https:// sites.google.com/a/concordia.sa.edu.au/exam-prepmths-apps/7-4-linear-correlation/interpreting-thecorrelation

Frost, J. (2020). Understanding Significance Levels in Statistics. Retrieved on August 31, 2020 from website: https://statisticsbyjim.com/hypothesistesting/significance-levels/

Goforth, C. (2015). Statistical Consulting Associate. Retrieved on August 23, 2020 from website, University of Virginia Library: https:// data.library.virginia.edu/using-and-interpretingcronbachs- alpha

Gulden Kaya Uyanik, N.G. (2013). A Study on Multiple Linear Regression Analysis. Science Direct, 106, 234-240. https://doi.org/10.1016/ j.sbspro.2013.12.027.

Havelock, R. (1973). Effective the Change Agent's Guide to Innovation. Englewood, New Jersey, USA: Educational Technology Publications.

Havelock, R. (2020). Change Agent's Guide. Retrieved on June 30, 2020 from website Organizational Change Management: Changeagentsguide.Com/Roles-Overview.

Havelock, R. and Zlotolow, S. (2021). Change Agent's Guide - Organizational Change Management. Retrieved July 4, 2021, From Change Agent's Guide from Website: https://changeagentsguide.com/

Ismail, R.K. (2012). Achievement Motivation in the Leadership Role of Extension Agent. United Kingdom: Cambridge Scholars Publishing.

Jabatan Pertanian Negeri Selangor. (2021). Retrieved February 8, 2021, from Selangor Website: https:// pertanian.selangor.gov.my/.

Kabir, S.M.S. (Ed.) (2006). Sample and sampling designs. In Basic Guidelines for Research: An Introductory Approach for All Disciplines. $1^{\text {st }}$ ed., p. 168-180. Chittagong, Bangladesh: Book Zone Publication.

Kim, J. (2015). How to Choose the Level of Significance: A Pedagogical Note. Retrieved from Munich Personal RePEc Archive website: https:// mpra.ub.uni-muenchen.de/69992/10/ MPRA_paper_69992.pdf

Krysik, J.1. and Finn, J. (2007). Research for effective social work practice. $1^{\text {st }}$ ed., p. 387. New York, USA: McGraw Hill.

Kunwar, N. (1989). Roles of field level agricultural extension workers in Nepal as perceived by agricultural extension personnel. 209. Retrieved on
July 16, 2020 from Website: http://lib.dr.iastate.edu/ rtd Part

Makapela, M. (2015). Effectiveness of Agricultural Extension Organisation in Rural Areas: The Case of Amathole District Municipality (Eastern Cape). South Africa: University of South Africa, MSc. Thesis.

Mcharo, A.C. (2013). Perception of Farmers on Effectiveness of Agricultural Extension Agents in Knowledge Transfer to Maize Growers in Kilindi District. Tanzania, Australia: University of Agriculture, MSa Thesis.

Pathak, H. (2010). Organisational Change. India: Pearson.

Radhakrishna, R.E., Yoder, E.P. and Baggett, C. (1991). Time management and performance. Journal of Extension, 29, 33-34.

Rohrich, R.J. and Sullivan, D. (2012). So, you want to be a change artist? Plastic and Reconstructive Surgery, 129(6), 1435-1437. https://doi.org/10.1097/ PRS.0b013e318251d45e

Ronald Havelock, H., Good, B.A. and Helper, P. (2020). Change Agent's Guide. Retrieved on February 21, 2021 from Website: https://changeagentsguide.com/

Saha, G.C. and Che Mat, R. (2018). A Study of Coconut Plantation Management Practice: Problems and Status presented at the SMMTC Postgraduate Symposium 2018, 18-19 March 2018. Kedah, Malaysia: Universiti Utara Malaysia.

Saidia, P.S., Chilagane, D.A., Wostry, A. and Fares, M.J. (2010). Evaluation of Effective Microorganisms (EM) Technology on Maize (Zea mays L.) Growth, Development and Yield in Morogoro, Tanzania. Research Report. Retrieved from website: https:// orgprints.org/id/eprint/19472/1/

EFFECTIVE_MICROORGANISMS_IN_AGRIC_S aidia et al 2010.pdf

Shah, J.A., Asmuni, A. and Ismail, A. (2013). Roles of Extension Agents Towards Agricultural Practice in Malaysia. International Journal on Advanced Science, Engineering, and Information Technology, 3(1), 59-63. https://doi.org/10.18517/ijaseit.3.1.278

USAID (2019). The coconut conundrum: how to scale up sustainable production? Retrieved on February 11, 2021 from USAID Website: https:// greeninvestasia.com/sustainable-coconut-andcoconut-oil-roundtable-event-proceedings/ 